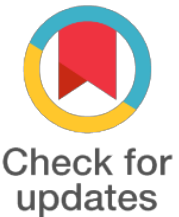

updates
*For correspondence:

thnhung@hcmus.edu.vn

Competing interests: The authors declare that no competing interests exist.

Received: 2017-08-08 Accepted: 2017-08-19

Published: 2017-09-05

Copyright The Author(s) 2017. This article is published with open access by BioMedPress (BMP).

This article is distributed under the terms of the Creative Commons Attribution License (CC-BY 4.0) which permits any use, distribution, and reproduction in any medium, provided the original author(s) and the source are credited.

\section{The efficiency of adipose-derived stem cell pretreated with hepatocyte growth factor and platelet rich plasma on a liver cirrhosis} mouse model

Yen Thi-Kim Nguyen, Nam Hai Nguyen, Trinh Van Le, Ngoc Hong Vo, Thanh Minh Dang, Huy Quang Do, Nhung Hai Truong

Laboratory of Stem Cell Research and Application, University of Science, Vietnam National University HCMC, Ho Chi Minh City, Vietnam

\section{Abstract}

Background: Because of their ease of isolation, high proliferation capacity in vitro, as well as their ability to differentiate into liver cells, Adipose-derived stem cell (ADSCs), are considered to be a promised candidate for liver disease treatment, including liver cirrhosis treatment. Recent studies show that hepatocyte growth factor (HGF) can stimulate ADSC to migrate to the injured areas and platelet rich plasma (PRP) can increase the stemness of ADSCs.

Method: In this study, we cultured ADSCs in the medium supplemented $20 \mathrm{ng} / \mathrm{ml}$ and $10 \%$ PRP; then transplanted them into the cirrhosis mouse model. After 11 weeks of $\mathrm{CCl}_{4}$ induction ( $1 \mathrm{ml} / \mathrm{kg}$, three times per week), mice were divided into 3 groups: (1) PBS group which were injected $0.2 \mathrm{ml} \mathrm{PBS;} \mathrm{(2)} \mathrm{ADSC} \mathrm{group} \mathrm{which}$ were transplanted $5 \times 105$ ADSCs non-pretreated with HGF and PRP; (3) ADSC/HGF+PRP group which were transplanted $5 \times 105$ ADSCs pretreated with HGF and PRP via the tail vein. We evaluated the effectiveness of the therapeutic at the day 7 th and 14 th after transplantation.

Results: The results show that the transplantation of ADSC pretreated with HGF and PRP after seven days improves the body weight (increase $4.673 \%$ ); decreases the ALT level $(p<0.05)$, the total leukocyte number $(p<0.05)$ and the expression of Pro-collagen (decrease 4.1 times) as well as $\alpha$-SMA (decrease 5.1 times), in comparison to the ADSC group. ADSCs pretreated with HGF and PRP also help to improve the liver tissue structure.

Conclusion: The therapy using ADSCs pretreated with HGF and PRP is considered to be a promising therapy. 


\section{Keywords}

Adipose-derived stem cell, hepatocyte growth factor, platelet rich plasma, liver cirrhosis mouse model, transplantation

\section{Funding}

This study was funded by Center of Science and Technology Development for Youth, Ho Chi Minh city

\section{References}

1. Koellensperger, E., et al. (2013), "Human adipose tissue derived stem cells promote liver regeneration in a rat model of toxic injury", Stem cells international, 2013

2. Neuss, S., et al. (2004), "Functional expression of HGF and HGF receptor/c-met in adult human mesenchymal stem cells suggests a role in cell mobilization, tissue repair, and wound healing", Stem cells, 22(3), 405-414

3. Truong, N.H., et al. (2014), "Establishment of a standardized mouse model of hepatic fibrosis for biomedical research", Biomedical Research and Therapy, 1(02), 43-49

4. Forte, G., et al. (2006), "Hepatocyte growth factor effects on mesenchymal stem cells: proliferation, migration, and differentiation", Stem cells, 24(1), 23-33

5. Wang, Y., et al. (2012), "Adipose derived mesenchymal stem cells transplantation via portal vein improves microcirculation and ameliorates liver fibrosis induced by $\mathrm{CCl}_{4}$ in rats", Journal of translational medicine, 10(1), 133 